\title{
TRABALHO IMATERIAL E SOFRIMENTO PSÍQUICO: O PÓS-FORDISMO NO JORNALISMO INDUSTRIAL
}

\author{
Carmem Lígia Iochis Grisci \\ PPGA/EA - Universidade Federal do Rio Grande do Sul, Porto Alegre, Brasil \\ Paulo Henrique Rodrigues \\ Fundação Roberto Marinho e Rede Globo, Rio de Janeiro, Brasil
}

\begin{abstract}
RESUMO: Este artigo reflete criticamente sobre implicações da recente fase do modo de produção capitalista nas rotinas de produção num jornal do Rio Grande do Sul. Trata-se de um estudo de caso cuja coleta de dados se deu através de investigação bibliográfica, seis entrevistas semi-estruturadas com jornalistas e observação não-participante. Como exercício teórico, é abordada a passagem da etapa fordista do capital para o pós-fordismo, enfatizando o conceito de compressão do tempo. Posteriormente, são analisados o deadline do periódico e as mudanças na atividade jornalística. Aqui, é traçada uma inter-relação entre as atuais rotinas de produção do jornalismo industrial e a emergência do trabalho imaterial na etapa recente do capital. Finalmente, através de estudos da subjetividade no trabalho, são analisadas as reações dos próprios jornalistas às transformações na organização do trabalho dentro da redação.
\end{abstract}

PALAVRAS-CHAVE: Trabalho imaterial; sofrimento psíquico; tempo; subjetividade.

\section{IMMATERIAL WORK AND PSYCHOLOGICAL SUFFERING: POST-FORDISM IN INDUSTRIAL JOURNALISM}

ABSTRACT: This article critically considers the implications of the recent phase of capitalist production modes in the production routines of a newspaper in Rio Grande do Sul. It is a case study in which data collection was based on bibliographic research, six semi-structured interviews with journalists and non-participative observation. As a theoretical exercise, the passage from fordist to post-fordist stages of capital will be dealt with, emphasizing the concept of time compression. The newspaper deadline and the changes in journalistic activity are analyzed. And, an interrelationship is traced between the present production routines of industrial journalism and the emergence of immaterial work in the recent stages of capital. Through studies of subjectivity in work, the reactions of the journalists themselves to the transformations in the work organization within the editorial staff are analyzed.

KEYWORDS: Immaterial work; psychological suffering; time; subjectivity.

Em O que é ser jornalista, Ricardo Noblat (2004) cita leis que devem ser seguidas por todos aqueles que optarem pela profissão. Uma delas refere-se à jornada de trabalho do jornalista. Nela, diz que o jornalismo é exercido em tempo integral: do momento em que o jornalista desperta até a hora em que vai dormir. Esta regra proposta por Noblat - jornalista com passagem por veículos como Veja, O Globo e Correio Braziliense - não é unanimidade entre seus colegas. Pelo menos é o que aparece quando estes são chamados a refletir sobre a organização do trabalho em que estão inseridos.

Apesar de tratar as tais regras como atemporais e intrínsecas ao jornalismo, este trabalhador em tempo integral de que fala $o$ autor pode ser ainda mais freqüente na atual etapa pós-fordista do capital. A reestruturação do modo de produção capitalista - esmiuçada por pensadores como Castells (2002) e Harvey (2004) - tem implicações sobre a organização do trabalho no jornalismo industrial.

Entre as características pós-fordistas nas rotinas de produção jornalística, a compressão do tempo se destaca. A nova concepção de temporalidade tem transformado a cadência nas redações de jornais. Citam-se aqui três desses imperativos: encurtamento e supervalorização do tempo de confecção do produto jornal (o deadline), alongamento da jornada de trabalho e desmantelamento dos limites entre funções.

Heloani (2003) apontou como a reestruturação produtiva tem transformado a organização do trabalho de jornalistas. Em sua tese, o autor, com um universo de sujeitos de 44 profissionais da imprensa paulista, indica como as transformações na produção têm afetado a qualidade de vida de jornalistas. $O$ presente artigo vem corroborar as preocupações apontadas por Heloani. A reflexão aqui feita permite apontar que as transformações na organização do trabalho no jornalismo industrial irromperam as fronteiras da imprensa do sudeste, berço do capitalismo brasileiro, e já ganha exemplo no sul do país. Eis o eixo principal deste exercício de reflexão.

É importante afirmar que este artigo se insere entre os estudos dispostos a analisar as transformações no jornalismo causadas pela reestruturação do capital. O trabalho de Fonseca (2005), cujo caráter panorâmico permite indicar os contornos pós-fordistas nas estruturas das empresas jornalísticas brasileiras, é referencial para este artigo. Para 
a autora, a organização do trabalho no jornalismo apresenta características capazes de retratar o novo modelo de desenvolvimento. Essas modificações na estrutura do jornalismo trariam implicações para o próprio conceito de jornalismo e de jornalista.

\section{Considerações Teóricas}

\section{O Pós-Fordismo no Jornalismo Industrial}

Harvey (2004) propõe 1973 como a data de uma guinada no modelo de desenvolvimento. Resumidamente, a soma de três importantes fatores teria dado cabo ao regime de acumulação fordista: crise do petróleo, fim do Acordo de Bretton Woods e endividamento dos Estados-nações. No Brasil, a transição ocorreu de forma peculiar.

Carvalho (1999) afirma que o fordismo no Brasil aconteceu de forma atrasada e caricatural. Quando EUA e Europa já se despediam do fordismo, o Brasil começava sua Idade do Ouro, o chamado Milagre Brasileiro, final da década de 70, período em que o Produto Interno Bruto oscilou em 7\% ao ano. Além do crescimento econômico, outra característica diferencia o fordismo brasileiro do modelo de desenvolvimento fordista americano e europeu: a inexistência de um Estado de Bem-estar. Durante o regime militar, apesar de extremamente interventor, política e economicamente, o Estado brasileiro nunca pôde ou quis atender a todas as demandas sociais da população.

Outro fator peculiar do fordismo caricatural, para usar a expressão cunhada pelo autor, foi a opção por uma política econômica que não repassava aos salários os ganhos de produção. Na contramão do que determina o fordismo genuíno, cuja valorização salarial está ligada à criação de um mercado de consumo em massa, no Brasil a concentração de renda foi vista como condição para o crescimento.

Enquanto a América do Sul vivia o fordismo, no Hemisfério Norte outros ventos já sopravam, balançando a estrutura do sistema.

A crise energética atingiu todas as economias em 1973. No ano da Guerra do Yom Kippur - conflito entre Israel, Egito e Síria -, as perfuradoras de petróleo tornaram-se armas. Os países árabes produtores organizaram um boicote em represália à ajuda americana dada ao lado israelense.

O rompimento do acordo de Bretton Woods, firmado após a $2^{\mathrm{a}}$ Guerra Mundial, agravava a crise. O dólar, a partir de então, deixava de ser a moeda de reserva no comércio mundial. Somados ao endividamento dos EUA, já maior economia global, o mundo mergulhou em uma crise que despertou mudanças na macroeconomia.

Na Europa, idéias semeadas por pensadores liberais apontam o Estado de Bem-estar como o vilão da crise, e agremiações como o Partido Conservador, do Reino Unido, e o Partido Republicano, nos EUA, assumem o comando.
Ambos os governos impõem transformações na macroeconomia. Alicerces do fordismo, como a indexação de salários e o caráter assistencial do Estado, vão sendo corroídos. Harvey (2004) aponta as consequiências para os trabalhadores.

Para os trabalhadores, tudo isso [transição para o regime de acumulação flexível, grifo nosso] implica uma intensificação dos processos de trabalho e uma aceleração na desqualificação e requalificação necessárias ao atendimento de novas necessidades de trabalho. A aceleração do tempo de giro na produção envolve acelerações paralelas na troca e no consumo. Sistemas aperfeiçoados de comunicação e de fluxo de informações, associados com racionalizações nas técnicas de distribuição... possibilitaram a circulação de mercadorias no mercado a uma velocidade maior (Harvey, 2004, p. 258).

Importante catalisador desta aceleração da produção não é omitido pelo autor: as novas tecnologias produtivas. Apesar de recente, datada no meio dos anos 90, a Internet se destaca na consolidação do modelo de desenvolvimento pós-fordista. Castells (2002) define aquilo que chama de Sociedade em Rede, ou Informacional - etapa em que a humanidade estaria inserida -, como a articulação entre uma nova fase do modo de produção capitalista e o avanço tecnológico.

A passagem do fordismo para o pós-fordismo não se deu imediatamente à crise dos anos 70 . Foram necessárias décadas de aperfeiçoamento político e econômico para que a rigidez fosse substituída pela flexibilidade na acumulação do capital. Para a adoção dessa forma flexível de acumulação do capital, Bauman (1999) diz que nações subdesenvolvidas têm um alto custo a pagar: abrir seus mercados e desistir de uma política econômica autônoma.

Nem todas as nações passam por modificações dessa ordem, parcial ou plenamente. Alguns países completaram seu ciclo, como EUA, Japão e Europa ocidental. Outras foram inseridas há apenas cerca de uma década, situação de economias latino-americanas como a do Brasil. Regiões da África ainda permanecem alheias aos ventos do liberalismo econômico.

Para que se entenda o quão transitória ainda é a passagem do fordismo para o pós-fordismo no Brasil, ressalta-se que só na última década os governos federais implementaram reformas de caráter liberal. As primeiras vieram sob o comando do presidente Fernando Henrique Cardoso (1995-2002), quando o Estado privatizou estatais de energia e telefonia. Quando Luiz Inácio Lula da Silva, em 2003, assume a Presidência República, continuam as transformações macroeconômicas rumo ao pós-fordismo. A reforma previdenciária de 2003 é um importante exemplo. Mas as transformações não cessam na estrutura macroeconômica. 
Segundo Harvey (2004), no pós-fordismo, toda a organização do trabalho passa a se alicerçar na flexibilização e na desregulamentação. Antes mesmo que sejam feitas modificações nas leis trabalhistas brasileiras, a flexibilização de contratos de trabalho, como a terceirização, e do próprio sistema funcional vem ocorrendo. Capparelli, em pesquisa sobre o jornal Zero Hora, já apontou a primeira reestruturação no jornalismo industrial.

\begin{abstract}
A primeira grande mudança foi o fim do copidesque nos anos 70, pois o jornal começou a contratar repórteres com texto final, submetidos a uma contagem periódica do número de laudas produzidas num determinado período de tempo. A informatização do jornal em 1988 reforçou essa tendência, com a utilização do texto já digitado pelo próprio repórter levando à despedida em massa de revisores, cargos privativos de jornalistas (Capparelli, 1997, p. 119).
\end{abstract}

A informatização não parou por aí. Logo, softwares mais avançados - editores de textos e programa de paginação - foram sendo adquiridos. Para Harvey (2004), a compressão do tempo-espaço está fortemente ligada ao alto investimento em tecnologia que possibilite automatizar tarefas, tornando-as mais ágeis e rápidas, permitindo que o trabalhador assuma outras. Além da sobreposição/supressão de funções, o apego à instantaneidade e a convergência de mídias são consequiências da ação da compressão do tempo nas rotinas de produção do jornalismo industrial.

\section{Trabalho Imaterial: Desdobramento do Capitalismo Pós-Fordista}

O trabalho imaterial é a interface da nova relação produção/consumo no capitalismo pós-fordista ou flexível. Sua emergência é um desdobramento claro das transformações por que passa o paradigma industrial.

"Na grande empresa reestruturada, o trabalho do operário é um trabalho que implica sempre mais, em diversos níveis, capacidade de escolher entre diversas alternativas e, portanto, a responsabilidade de certas decisões" (Lazzarato \& Negri, 2001, p. 25).

Para Lazzarato e Negri (2001), é o trabalho imaterial que ativa e organiza a relação produção/consumo. A ativação da relação social com o consumidor é materializada dentro e através do processo comunicativo. O trabalho imaterial inova continuamente as formas e as condições da comunicação, dá forma e materializa as necessidades, o imaginário e os gostos do consumidor. A particularidade da mercadoria produzida pelo trabalho imaterial está no fato de que ela se destrói no ato do consumo, mas alarga, transforma, cria o ambiente cultural do consumidor. Ela transforma o seu utilizador.

Há três tipos de trabalho imaterial: o primeiro, resultante de um imbricamento entre produção fabril e a pro- dução de serviços, sendo que a primeira tende a assumir características da segunda; o segundo, que é o correspondente às tarefas analíticas e simbióticas; por fim, o terceiro é o que envolve a produção e a manipulação de afetos, além do trabalho do tipo físico.

\section{Psicodinâmica do Trabalho \\ e Atividade Jornalística}

Imersa na nova economia capitalista, a empresa jornalística pesquisada adota cada vez mais ferramentas de gestão que a tornem atraente ao capital financeiro e, logo, mais lucrativa. Mas o jornalismo pós-fordista exige seu preço, cujas conta e fatura têm como destinatários, em parte, os próprios jornalistas.

\begin{abstract}
Hoje, afora o objetivo principal - o lucro -, o que caracteriza uma empresa não é mais sua produção, não é mais o trabalho. O que a caracteriza é sua organização, sua gestão, seu gerenciamento. Propõe-se assim um deslocamento qualitativamente essencial. O tema da organização da empresa substitui-se ao tema do trabalho nas práticas discursivas do neoliberalismo (Dejours, 2003, p. 41).
\end{abstract}

Submetidos a um ritmo de trabalho eletrizante, sobrecarregados pela tecnologia e conscientes do grau de precarização do trabalho que faz despencar seu poder de reivindicação, os jornalistas enfrentam desafios no trabalho que atingem sua saúde.

Perceber e relatar como os jornalistas encaram este ataque à saúde é importante para entender a nova concepção de jornalismo. Serve mesmo como contribuição à compreensão da atual etapa capitalista. Quando o sofrimento psíquico no trabalho é visto como objeto de estudo, cabe à psicodinâmica do trabalho refleti-lo.

Originária da psicopatologia do trabalho, cujos estudos surgiram no pós-guerra, a psicodinâmica está em desenvolvimento. Seu passado breve não permite concluir que lhe falte sustentação científica. $\mathrm{O}$ empenho com que pesquisadores têm se dedicado à psicodinâmica faz dela um campo científico consolidado.

Este artigo se referencia, predominantemente, das discussões inferidas pelo psiquiatra francês Christophe Dejours. No entanto, pesquisadores alheios ao campo da psicodinâmica, como Annie Thébaud-Mony, Richard Sennett e Denise Sant'Ana, também são referências de autores que discutem a organização do trabalho.

A partir do conceito de sofrimento psíquico adotado por Dejours, tenta-se interpretar a reflexão que os jornalistas fazem da sua organização do trabalho.

\section{Procedimentos Metodológicos}

Esta pesquisa não busca a produção de uma teoria generalizante. Quer apenas contribuir com a reflexão sobre as 
mudanças na rotina de produção do jornalismo industrial. Desta vez o foco é um jornal do sul do país. Trabalho semelhante e mais bem fundamentado foi feito por Heloani (2003) no sudeste do Brasil.

\section{O Jornal Pesquisado}

Com mais de 40 anos de história, o jornal estudado é considerado o maior do sul do país. Na redação, trabalham cerca de 200 jornalistas, e a tiragem atinge os $300 \mathrm{mil}$ exemplares no domingo.

\section{Estudo de Caso}

Para tentar responder satisfatoriamente ao problema de pesquisa, opta-se pelo estudo de caso na concepção dada por Yin (2001). O autor acredita que, quando bem empregado, o estudo de caso permite elucidar dados e responder a questionamentos.

\section{O estudo de caso é a estratégia escolhida ao se exami- narem acontecimentos contemporâneos, mas quando não se podem manipular comportamentos relevan- tes. O estudo de caso conta com muitas técnicas uti- lizadas pelas pesquisas históricas, mas acrescenta duas fontes de evidências que usualmente não são incluídas no repertório de um historiador: observa- ção direta e série sistemática de entrevista (Yin, 2001, p. 27).}

A investigação bibliográfica é responsável por definir o referencial teórico; neste caso, a Escola Francesa de Regulação, a noção de trabalho imaterial e a psicodinâmica do trabalho.

\section{Coleta de Dados}

A coleta de dados deu-se através da observação nãoparticipante e de entrevistas semi-estruturadas. Visitas à redação do jornal, com observação e conversas informais com jornalistas no momento em que trabalhavam, foram cruciais para o entendimento da engenharia das rotinas de produção do jornal. Deu-se prioridade às questões que envolvessem diretamente o deadline.

Foram realizadas seis entrevistas semi-estruturadas com jornalistas, três mulheres e três homens, que foram gravadas, transcritas e analisadas qualitativamente. Todos participantes foram escolhidos aleatoriamente. Eles foram submetidos a um questionamento que, apesar de estabelecido através de um roteiro, permitia-lhes ultrapassar as balizas das perguntas.

Sem dúvida, mesmo que soe indevido estabelecer uma escala de valor, as entrevistas foram a mais bem sucedida escolha metodológica. A dedicação com que os sujeitos refletiram sobre a organização do trabalho tornou fácil a confecção dos resultados. É como se houvesse uma demanda (Dejours, 1999), uma ânsia por narrar sua experiência no trabalho e - principalmente - a angústia com as transformações nas rotinas de produção.
Há dois importantes assinalamentos a serem feitos sobre as entrevistas. Primeiro, o fato de um dos autores ser colega de trabalho dos entrevistados. Segundo, as entrevistas foram feitas em um lugar com isolamento sonoro, mas dentro da redação. Aqui, adianta-se um dos resultados da pesquisa que justificam o fato de as entrevistas terem se realizado no ambiente de trabalho. A jornada esticada tornou-se impeditivo para que se fizessem entrevistas fora da redação. Os jornalistas viam comodidade em concedêlas em intervalos de trabalho.

\section{Escuta Comprometida}

O sofrimento psíquico no trabalho não é um objeto de estudo como um outro qualquer (Dejours, 1999). A pesquisa em psicodinâmica do trabalho exige do pesquisador uma postura maior do que um simples ouvinte.

\begin{abstract}
Falar e ser ouvido parece ser o modo mais poderoso de pensar e, portanto, de refletir sobre a própria experiência, desde que se esteja comprometido em relação dialógica, intersubjetiva, na qual se acredita que o outro esteja de fato tentado a compreender. É ao explicar a outrem o meu sofrimento, a minha relação com o trabalho, que eu, perplexo, me ouço dizer coisas que eu não sabia, até tê-las dito (Dejours, 1999, p. 176).
\end{abstract}

Como salienta o próprio autor, quem fala sobre seu sofrimento sempre procura amenizá-lo, no entanto, o pesquisador não oferece soluções. A missão é auxiliar os próprios atores sociais na busca de uma mediação sobre o seu estar no mundo.

\begin{abstract}
Os trabalhadores são as pessoas mais indicadas para encontrar as soluções e oferecer sugestões para transformar a organização do trabalho. A dificuldade, quando surge, nasce de eles não mais se sentirem capazes de analisar a situação em que se encontram. Neste caso, cabe-nos propor que tentem compreender essa situação; e apresentar a hipótese de que, se conseguirem entender melhor os dados da situação, eles mesmos terão idéias sobre como transformar a organização do trabalho. Em termos mais gerais, pode-se dizer que nós não interviríamos se não tivéssemos certeza de que os próprios trabalhadores conseguirão encontrar respostas (Dejours, 1999, p. 168).
\end{abstract}

As transcrições das entrevistas foram analisadas, primeiramente, individualmente, depois, em cruzamento. O objetivo foi identificar na reflexão que os jornalistas faziam da organização do trabalho na redação pontos que explicitassem sofrimento psíquico. Pontos de conflito entre vida e trabalho indicados pelos participantes: sensações de desconforto - físico e psíquico -, taquicardia, decepção com a profissão, reivindicações caladas, inspirações frustradas, impactos na vida social.

Para segurança dos sujeitos, são usados pseudônimos, e o nome do jornal, suprimido. 
A escolha metodológica pode permitir avançar no estudo da organização da atividade jornalística na nova etapa capitalista. Como enfatiza Deslandes (1994), as considerações feitas sobre a realidade estudada são sempre menos precisas do que a própria realidade.

\section{Apresentação dos Resultados}

\section{Jornalismo Pós-Fordista e Trabalho Imaterial}

As liberdades ampliadas anunciadas como vantagem do trabalho imaterial são perceptíveis na redação do jornal. A sobreposição/supressão de funções e o processo multimídia permitem diminuir a alienação do trabalho e das fronteiras, solicitando iniciativa, cooperação, domínio do processo, tomada de decisão, envolvimento afetivo, mobilidade. A preocupação com o leitor também descreve a emergência do trabalho imaterial na redação. Este aspecto é composto pela valorização do atendimento ao leitor e da velocidade na produção do jornal. Tem-se no jornalismo industrial pós-fordista uma incidência clara da lógica da urgência.

A horizontalização da organização do trabalho abre espaço, hoje, para que um repórter possa editar sua matéria e diagramá-la. Ao mesmo tempo em que ameniza a alienação do processo, dando ao trabalhador oportunidade de entender toda a cadeia produtiva, exige maior comprometimento e responsabilidade. A mobilidade, a disponibilidade irrestrita para o trabalho, a exigência de criatividade e cordialidade são condizentes com o trabalho imaterial (Lazzarato \& Negri, 2001).

A preocupação com o leitor também chega às redações. $\mathrm{O}$ bom atendimento do leitor passa a se incorporar como tarefa do jornalista. Assim como Grisci (2004) percebeu no setor bancário, da perspectiva dos consumidores em jornal, a gestão da intimidade, característica do trabalho imaterial, se dá pelas atenções e tratamentos dispensados ao leitor, que lhe gerará sentimento de conforto, satisfação, segurança.

Este jornalismo pós-fordista assemelha-se mais ao trabalho imaterial que ao jornalismo hierarquizado, quando repórter, editor e diagramador eram funções limítrofes e a redação era enxergada pelo leitor como algo inatingível. Hoje, os telefones amplamente divulgados pelo próprio jornal - sem considerar a seção do leitor, que tem página específica no corpo do diário - tornam a redação próxima do leitor, a uma chamada de distância.

O jornalismo hoje mobiliza ainda mais relações intelectuais e afetivas dos trabalhadores em geral, embora também produza um bem: a notícia. Produzir informação significa produzir valores, cuidado, tranqüilidade, sentimento de bem-estar, interação humana e - principalmente - velocidade. “... na sociedade de controle o tempo é da ordem da instantaneidade, da aceleração, e os novos pa- drões tecnológicos e organizacionais proporcionam a experimentação de um tempo calcado na coexistência e na vigilância contínua" (Grisci, 2004, p. 4).

Estar informado antes de todos: este produto do trabalho imaterial tornou o tempo nas redações ainda mais precioso. Na redação, a racionalização científica do tempo é explícita em tabelas adotadas para cronometragem do baixamento de páginas. Esta lógica atesta o crescimento da preocupação com o deadline nas redações e mostra a sua supervalorização.

Essa aceleração do processo de produção é percebido pelos jornalistas de tal forma que às vezes ultrapassa as conversas de corredor e pára nas páginas do jornal. Uma colunista, que acumula a função de editora do suplemento cultural do jornal, relatou numa crônica: "Ainda não fazia parte dos meus planos ser jornalista, uma profissão que não me ofereceria muitas oportunidades para cenas slow motion". E completou: "Não me espanta que tenha partido de um jornalista a idéia de lançar um movimento internacional contra a pressa".

Consequiência da compressão do tempo-espaço, que desvaloriza o espaço, o ritmo frenético na redação é imposto para que garanta a chegada cedo do jornal às casas dos assinantes. A distância entre a sede do jornal e a casa do leitor não é mais justificativa para atrasos. A luta contra o atraso começa dentro da própria redação.

"O trabalho imaterial produz acima de tudo uma relação social (uma relação de inovação, de produção, de consumo) e somente na presença desta produção a sua atividade tem um valor econômico" (Lazzarato \& Negri, 2001, p. 46).

Ojornalismo imaterial não produz apenas notícia, vende velocidade.

\section{A Organização Pós-Fordista \\ do Trabalho na Redação}

Através das respostas dos entrevistados, identificam-se alguns dos fatores preponderantes na relação do jornalista com seu trabalho. Além da discussão sobre sofrimento psíquico, analisa-se essa relação a partir da abordagem de autores que refletem sobre a pós-modernidade. Essas interpretações permitem compreender as implicações da transformação por que passa o capitalismo na atividade jornalística, objetivo principal deste artigo.

“... As rotinas incessantes de produção... acabam não permitindo a reflexão dessas práticas... exatamente o que esse trabalho pretendeu fazer" (Roese, 2003, p. 66). Quando encerra assim seu estudo sobre a seleção de notícias da editoria Geral de Zero Hora, o autor reconhece a capacidade que a rotina pode ter de tolher qualquer tipo de reflexão sobre a produção dentro da redação. Já Moretzsohn (2002), na pesquisa sobre jornalismo em tempo real, deixa claro que o ritmo jornalístico não vendou seus olhos. "Esta 
pesquisa começou a tomar forma ainda em meus tempos de repórter, nos anos 80, quando observava (e sofria) o ritmo das rotinas de trabalho em grandes redações do Rio" (p. 5).

A ausência de reflexão sobre a organização do trabalho não está restrita ao cotidiano de uma redação. Como todos os outros trabalhadores, jornalistas mantêm com o seu trabalho uma relação que vai além do simples cumprimento de uma atividade. Como afirma Dejours (2003), trabalhar não é apenas exercer um ofício, é também vivenciar. É no ambiente de trabalho que o trabalhador enfrenta o real, constrói o sentido do trabalho, vive com o outro, vive a pressão e vivencia o prazer e o sofrimento.

Enquanto fator de construção identitária, a representatividade que o trabalho tem para o trabalhador é um importante campo para a reflexão das transformações na sociedade. Neste estudo, através da reflexão dos jornalistas entrevistados, pode-se identificar com clareza o que Capparelli (1997) chama de jornalismo pós-fordista. Pensar sobre a organização do trabalho pode ser o primeiro passo dos trabalhadores visando a melhorias.

A falta de reflexão sobre a organização do trabalho tem implicações que vão além do próprio entendimento da produção.

A nova instantaneidade do tempo muda radicalmente a modalidade do convívio humano - e mais conspicuamente o modo como os humanos cuidam (ou não cuidam, se for o caso) de seus afazeres coletivos, ou antes o modo como transformam (ou não transformam, se for o caso) certas questões em questões coletivas (Bauman, 2001, p. 147).

Os jornalistas responderam a perguntas elaboradas para que refletissem sobre as rotinas de produção. As citações mostram os contornos da organização do trabalho na redação. A partir das respostas, procura-se analisar questões propostas por alguns autores como sendo próprias da organização do trabalho pós-fordista ou imaterial.

Com as entrevistas pôde-se notar aspectos como o absenteísmo, o sofrimento psíquico e a corrosão do caráter, de que fala Sennett (2000).

\section{Sobreposição/Supressão de Funções e o Processo Multimídia}

A questão Como é o teu trabalho?, que abriu todas as entrevistas, surpreendeu os entrevistados. Surpreendentes também foram as respostas. Alguns deixam nítidas as transformações por que passa a atividade jornalística, principalmente pelo agregar de funções. Para Sennett (2000), a organização pós-fordista do trabalho pode ser corrosiva para o caráter. Segundo o autor, se no fordismo, o trabalhador tinha que confiar no outro para fazer seu trabalho, na etapa pós-fordista, com o fim da linha de montagem, a confiança perde sua importância.
"Aqui existe um acúmulo de funções similares", diz Irene. Ela aborda de maneira crítica a sobreposição de funções: "Eu não vejo vantagem nenhuma. Tu trabalhas muito mais para produzir uma página sozinho. E a chance, a margem de erros aumenta muito". Do processo multimídia, vê vantagem econômica - para a empresa: "Isso daí é outra coisa. Já é a terceira via de uma exploração muito maior... Descobriram um novo caminho de exploração de mão-de-obra". Apolo concorda: “A gente sabe que isso é uma forma de economizar mão-de-obra. É um processo que acaba permitindo à empresa aumentar seus rendimentos". Ele argumenta: "A gente está trabalhando, além de trabalhar para o jornal, para a rádio, às vezes para a TV. As nossas matérias são sempre publicadas no site."

Outros, como aponta Sennett (2000), vêem no acúmulo uma forma de libertação do trabalho do outro. "Às vezes é mais fácil fazer aquilo que era para outro personagem da linha de montagem, digamos, do que esperar esse personagem chegar", acredita Hermes. Íris vai além: “Acho que a gente está caminhando para que os editores já desenhem as suas páginas independentemente do diagramador. Que eles não me ouçam, os diagramadores, mas seria o paraíso. Porque tu não dependes de outras pessoas." "A vergonha da dependência tem uma consequiência prática. Corrói a confiança e o compromisso mútuo, e a ausência desses laços ameaça o funcionamento de qualquer empreendimento coletivo" (Sennett, 2000, p. 169).

A sobreposição parece criar novas funções. É o que percebe Perseu ao descrever como é seu trabalho.

Hoje, com a fusão que existe entre edição e diagra-
mação, a gente acaba falando: eu vou editar grafica-
mente o jornal... É uma fusão que acontece dentro
de um sistema que a gente conhece no dia-a-dia.
Ela não está no papel. Hoje, no papel, diagramador
$e ́$ diagramador, editor é editor.

Perseu dá nome à nova função: “... o editor-gráfico, que eu prefiro até chamar assim”. Sua experiência permite rememorar como funcionava parte da rotina de produção no jornal - quando confiar no trabalho do outro era imprescindível.

O diagramador era os olhos do editor. Nós não tínhamos à nossa frente a tela do computador onde você ia desenhando, e a página ia se formando. Nós tínhamos um papel... Cada diagramador que riscava, que desenhava a página, ele tinha que ter essa visão. $O$ editor ficava do lado olhando e tinha que acreditar naquilo ali.

A reflexão de Hera resume o pós-fordismo na rotina de produção do jornal: "Atualmente, o meu trabalho é um pouco multidisciplinar... porque faço desde a reportagem até a edição". 


\section{Absenteísmo no Trabalho}

Trabalhar doente vem se tornando uma prática comum em empresas pós-modernas (Dejours, 2003). Outros autores também têm apontado a queda do absenteísmo como característica da organização do trabalho no capitalismo pós-fordista.

"Vivemos numa cultura em que a vergonha de estar doente parece ter sido naturalizada, talvez seja apenas desculpável se queixar da dor quando se é criança, quando nãoé totalmente responsável pelo próprio corpo" (Sant'ana, 2001, p. 33).

Dejours (2003) acredita que os próprios ganhos da produtividade resultam "essencialmente da diminuição do absenteísmo, da redução dos custos da mão-de-obra e da inexistência de movimentos reivindicativos, mais que da melhoria da qualidade" (Dejours, 2003, p. 51). No jornalismo parece não ser muito diferente, como relata uma entrevistada:

Eu tenho tendinite há muito tempo. Estou trabalhando normalmente. Deveria ter feito dez sessões de fisioterapia. $O$ papel está ali na minha bolsa. E não é a empresa que me diz: não vá fazer. Na verdade sou eu que não me permito fazer porque tenho uma série de coisas para fazer e eu vou fazendo.

"Quando eu trabalho cinco horas, eu saio daqui frustrada, com a sensação de que fiz pouco. Saio com culpa, pensando: puxa, hoje eu não mereci meu salário!". Neste e no depoimento que segue, Íris vê como impensável uma rotina de trabalho saudável:

Tu não podes querer, num período de eleição, dormir oito horas por dia e ir de manhã ao parque. Não pode querer ter uma vida normal. Mas eu não chego a achar que seja uma coisa sobre-humana. Só acho meio insano, às vezes.

Trata-se, certamente, de atender às novas demandas do trabalho imaterial, que, se, por um lado, incentiva tomadas de decisão e parcelas de autonomia, mesmo que outorgada, por outro, instala nos trabalhadores um engajamento irrestrito à lógica da produção urgente.

\section{O Sofrimento Psíquico de Jornalistas}

Quando se fala em sofrimento psíquico no trabalho, deve-se entender duas coisas. Primeiro, para a psicodinâmica do trabalho, o sofrimento é um estado mental que implica um movimento reflexivo da pessoa sobre seu estar no mundo. Dejours (1999) ressalta que o sofrimento psíquico é sempre individual e único. Segundo, o sofrimento psíquico é responsável por impelir o sujeito no trabalho, em busca das condições de auto-realização. A idéia de compressão do tempo-espaço na rotina de produção é exemplar para se entender o sofrimento psíquico na redação. A pressão do deadline desponta, mas outro aspecto da atividade jornalística é apontado pelos sujeitos como incidente nas suas vidas: a jornada de trabalho. As horas de trabalho de um jornalista não podem exceder, conforme a lei trabalhista brasileira, cinco horas. Pode ser elevada até sete horas, mediante acordo que estipule pagamento extra.

O ritmo rápido de trabalho e a jornada extensa não são apenas importantes provocadores de sofrimento psíquico na redação. A convergência entre os dois fatores é vista pelos jornalistas como uma das principais causas de abandono da profissão.

"As cinco horas de jornalismo só existem no papel e, mesmo assim, nem no papel, porque ninguém obedece. Não existe pagamento de hora extra", diz Hera.

Eu fico em média umas dez horas por dia dentro da redação. Eu acredito que o ideal seria ficar oito, no máximo... Duas horas [a mais] por dia é muita coisa. Até porque não é uma questão só de tempo. É que eu saio do jornal com o cérebro como um suco (Hermes).

"O sofrimento é sempre, antes de tudo, um sofrimento do corpo, engajado no mundo e nas relações com os outros" (Dejours, 1999, p. 19). Apolo concorda:

Não existe hora extra. Honestamente, não conheço ninguém que fique no jornal porque quer ficar no jornal trabalhando. Óbvio que todos nós amamos nosso trabalho, o ambiente é interessante, mas isso não justifica que a pessoa abra mão da sua vida pessoal para ficar no trabalho.

Apolo acha que o salário contribui para o desencanto com o jornalismo: "Realmente, é um salário baixo, e existe muita cobrança. É uma responsabilidade muito grande, e a carga horária se estende por um período muito além do normal". A desistência de alguns colegas, apesar de muitas vezes ser velada já que, conforme um deles, "ninguém quer sair de mal com a empresa", sempre tem sua causa consciente. "Claro que a gente sabe que se em outros lugares não fosse diferente as pessoas não sairiam, se houvesse um ritmo de trabalho menor, se o salário fosse mais alto", explica Apolo.

Hoje, a gente tem um deadline muito mais rigoroso do que era antes. Antes, se tinha, mas tu tinhas jogo de cintura... era um pouco mais flexível do que agora. Agora é fechou, fechou. Às vezes te arrancam uma página da mão e sai do jeito que foi (Íris).

Dejours (1994) explica por que o deadline causa tanto sofrimento: "quando uma tarefa deve ser realizada sob certa pressão de tempo, ocasionando expectativas, standby, tempos mortos e depois uma ação concentrada de esforço desgastante, surgem tensões e irritações" (p. 102). "Se tu trabalhas com tempo muito exíguo perto do horário do fechamento, então a pressão é bem maior. Tu estás com o editor em cima de ti, te cobrando a matéria, enfim", conta Apolo. 
O que se pode chamar de contradição tecnológica parece ser causa de sofrimento entre os jornalistas. A porosidade na rotina de trabalho, que seria uma das benesses do avanço tecnológico, é reivindicada. Eles só não entendem (ou preferem não entender) que o ritmo incessante da redação é mais culpa da gestão da tecnologia, que do próprio investimento em softwares. "Não vejo as pessoas trabalharem menos hoje. Pelo contrário, a gente tem o computador e trabalha mais. E cada vez trabalha mais. Porque tu cada vez tens mais acesso a coisas", expõe Íris. Hermes completa:

Mesmo que a tecnologia tenha avançado sobre os veículos de comunicação, a tecnologia, ao mesmo tempo em que abreviou e cortou etapas, impôs um ritmo acelerado nas empresas de comunicação e também uma exigência maior do consumidor e da concorrência, de o produto chegar com mais agilidade.

Tanto o deadline mais rígido quanto o ritmo e a jornada da atividade jornalística escondem preocupações dos trabalhadores da notícia. Íris diz temer que o excesso de planejamento do deadline e a rigidez com que vem sendo imposto acabem fazendo "a gente virar um burocrata".

Se antigamente as redações eram insalubres porque te afetavam o ouvido de barulheira de máquina e tal, ou o teu pulmão, porque todo mundo fumava que nem doido; hoje, a insalubridade é mais perigosa, porque é uma insalubridade invisível, que é a do teu cérebro, da tua mente. Eu acho que a redação, hoje, convida... uma legião de pessoas a terem problemas psicológicos (Hermes).

O sofrimento não exclui o prazer (Dejours, 1994). Mesmo submetidos a ritmos incessantes dentro da redação, jornalistas gostam do que fazem, isso é inegável. A própria adrenalina nos horários críticos do baixamento foi indicada por alguns como prazerosa e intrínseca à profissão, o que parece revelar um fator de construção de identidade ligado ao tempo. Nas entrevistas, isso ficou claro em alguns momentos. O exagero na hora de falar da paixão pelo jornalismo-expressão usada pelos seis entrevistados - como justificativa para suportar o ritmo frenético, a jornada comprida e o salário minguado, também tem ares de estratégia coletiva de defesa (Dejours, 2003). Porém, para sanar essa dúvida, não só o tempo, como o número de participantes teria de ser maior.

A normalidade é interpretada como o resultado de uma composição entre o sofrimento e a luta (individual e coletiva) contra o sofrimento no trabalho. Portanto, a normalidade não implica ausência de sofrimento, muito pelo contrário. Pode-se propor um conceito de normalidade sofrente, sendo, pois, não $o$ efeito passivo de um condicionamento social, $e$ sim o resultado alcançado na dura luta contra a desestabilização psíquica provocada pelas pressões do trabalho (Dejours, 2003, p. 36).
Mas a reflexão sobre a construção da identidade de jornalista fica para uma outra pesquisa.

\section{Considerações Finais}

A passagem do capitalismo pesado para o leve, como adjetiva Bauman (2001), é um processo em curso no Brasil atualmente. Em razão disso, precisa ser mais bem avaliado nos seus desdobramentos. Estar no meio do processo pode tornar a reflexão menos totalizante.

Tendo como referencial teórico autores que se detêm à análise da compressão do tempo e à reestruturação do trabalho, pode-se dizer que esta pesquisa indica, ao menos, a emergência de características pós-fordistas na organização do trabalho, como a imaterialidade - com implicações reais sobre a vida do trabalhador da notícia.

A horizontalização da produção no jornalismo - sobreposição/supressão de funções, encurtamento do processo de produção de notícias verificado através da antecipação e planejamento do deadline e avanço rumo à chamada multimídia - comprova, na perspectiva da Economia Política da Comunicação, uma reestruturação do modo de produção.

Em momento algum se quis criticar o avanço tecnológico. A tecnologia é vista por esta pesquisa como importante fator na compressão do tempo, e não vilã da sobrecarga de trabalho. Se se procura um vilão, este pode ser identificado na racionalidade dominante neste ciclo do capital, que tem na japonização da gestão um de seus principais desdobramentos. Mergulhadas em teses de produtividade, sob a lógica da urgência, empresas têm contribuído ainda mais para o crescimento de doenças relacionadas ao trabalho.

O fato de que o trabalho imaterial produz ao mesmo tempo subjetividade e valor econômico demonstra como a produção capitalista tem invadido toda a vida e superado todas as barreiras que não só separavam, mas também opunham economia, poder $e$ saber (Lazzarato \& Negri, 2001, p. 47).

A hipersolicitação do trabalhador, que, como foi visto, não poupa os jornalistas, merece atenção especial de estudiosos. Como afirma Thébaud-Mony (2004), há um verdadeiro silêncio sindical, jurídico, político e médico frente a esta característica advinda com a busca por maior produtividade. Hoje, "o único limite à hipersolicitação de homens e mulheres no trabalho situa-se no ponto de ruptura: o acidente, a tendinite, a Síndrome do Túnel de Carpo..." (Thébaud-Mony, 2004, p. 16). É preocupante que o único limite à intensificação do trabalho seja o adoecimento.

\section{Referências}

Bauman, Z. (1999). Globalização: As conseqüências humanas. Rio de Janeiro, RJ: Jorge Zahar. 
Grisci, C.L.I.; Rodrigues, P.H. "Trabalho Imaterial e Sofrimento Psíquico: O Pós-Fordismo no Jornalismo Industrial"

Bauman, Z. (2001). Modernidade líquida. Rio de Janeiro, RJ: Jorge Zahar.

Capparelli, S. (1997). Zanzibar de novas tecnologias: Imprensa regional e Zero Hora. In Temas contemporâneos em Comunicação (pp. 109-126). São Paulo, SP: Edicom/Intercom.

Carvalho, M. P. de. (1999). O fordismo no Brasil. Que fordismo é esse? In M. F. M. de Oliveira \& L. Rodrigues (Eds.), Capitalismo: Da gênese à crise atual (pp. 91-132). Montes Claros, MG: Unimontes.

Castells, M. (2002). Sociedade em rede. São Paulo, SP: Paz e Terra.

Dejours, C. (1994). Trabalho e saúde mental: Da pesquisa à ação. In M. I. S. Betiol. Psicodinâmica do trabalho: Contribuições da Escola Dejouriana à análise da relação prazer, sofrimento e trabalho. São Paulo, SP: Atlas.

Dejours, C. (1999). Conferências brasileiras: Identidade, reconhecimento e transgressão no trabalho. São Paulo, SP: Fundap.

Dejours, C. (2003). A banalização da injustiça social. Rio de Janeiro, RJ: Editora da Fundação Getúlio Vargas.

Deslandes, S. F. (1994). A construção do projeto de pesquisa. In M. C. de S. Minayo (Ed.), Pesquisa social: Teoria, método e criatividade (pp. 31-50). Petrópolis, RJ: Vozes.

Fonseca, V. P. da S. (2005). Jornalismo no conglomerado de mídia: Reestruturação produtiva sob o capitalismo global. Tese de Doutorado não-publicada, Programa de Pós-graduação em Comunicação e Informação, Universidade Federal do Rio Grande do Sul, Porto Alegre, RS.

Grisci, C. L. I. (2004). Trabalho imaterial, controle e subjetividade na reestruturação produtiva bancária. In Associação Nacional de Pós-Graduação e Pesquisa em Administração (Ed.), Anais do XXVIII Encontro Nacional de Programas de Pós-Graduação em Administração, Curitiba, PR: Enanpad.

Harvey, D. (2004). Condição pós-moderna: Uma pesquisa sobre as origens da mudança cultural. São Paulo, SP: Loyola.

Heloani, J. R. (2003). Mudanças no mundo do trabalho e impactos na qualidade de vida do jornalista. Tese de Pós-Doutorado, Escola de Administração de Empresas de São Paulo, Fundação Getúlio Vargas, São Paulo, SP.

Lazzarato, M., \& Negri, A. (2001). Trabalho imaterial: Formas de vida e produção de subjetividade. Rio de Janeiro, RJ: DP\&A.

Moretzsohn, S. (2002). Jornalismo em "tempo real": O fetiche da velocidade. Rio de Janeiro, RJ: Revan.

Noblat, R. (2004). O que é ser jornalista: Memórias profissionais de Ricardo Noblat. Rio de Janeiro, RJ: Record.
Roese, L. N. (2003) Seleção de notícias: O caso da editoria Geral de Zero Hora. Monografia não-publicada, Faculdade de Biblioteconomia e Comunicação, Universidade Federal do Rio Grande do Sul, Porto Alegre, RS.

Sant'ana, D. B. de. (2001). Corpos de passagem: Ensaios sobre a subjetividade contemporânea. São Paulo, SP: Estação Liberdade.

Sennett, R. (2000). A corrosão do caráter: As conseqüências pessoais do trabalho no novo capitalismo. Rio de Janeiro, RJ: Record.

Thébaud-Mony, A. (2004). Relações sociais e instituições de prevenção na França frente à intensificação do trabalho. In A. R. C. Merlo (Ed.), Saúde e trabalho no Rio Grande do Sul: Realidade, pesquisa e intervenção (pp. 15-21). Porto Alegre, RS: Editora da Universidade Federal do Rio Grande do Sul.

Yin, R. K. (2001). Estudo de caso: Planejamento e métodos. Porto Alegre, RS: Bookman.

Carmem Ligia Iochins Grisci é Psicóloga, Doutora em Psicologia, Professora do Programa de Pós-Graduação da Escola de Administração da Universidade Federal do Rio Grande do Sul (PPGA/EA/UFRGS). Pesquisadora CNPq. Endereço para correspondência: Av.Washington Luiz, 855, prédio13701, sala 424, UFRGS, Porto Alegre, RS, 90010-460. cligrisci@ea.ufrgs.br

Paulo Henrique Rodrigues é Jornalista graduado pela UFRGS, e, atualmente, é repórter e roteirista do programa Globo Ecologia, da Fundação

Roberto Marinho e Rede Globo.

Endereço para correspondência: Rua Pena Chaves, 73/ 301, Jardim Botânico, Rio de Janeiro, RJ, 22460-090.

ph.rodrigues@globo.com

\section{Trabalho Imaterial e Sofrimento Psíquico: O Pós-Fordismo no Jornalismo Industrial}

Carmem Lígia Iochis Grisci e Paulo Henrique Rodrigues Recebido: 31/05/2006

$1^{\text {a }}$ revisão: 20/11/2006

Aceite final: 23/01/2007 